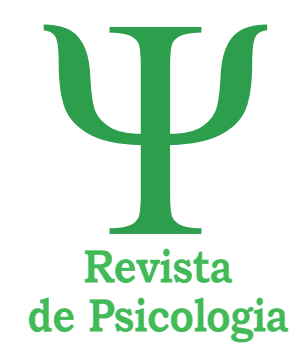

ISSN 2179-1740

\section{ALHURES DA LOUCURA: UM ESTUDO ARQUEOGENEALÓGICO SOBRE A PRODUÇÃO DA FIGURA DO DOENTE MENTAL}

\author{
ELSEWHERES OF MADNESS: AN ARCHEOGENEALOGICAL STUDY ABOUT THE \\ PRODUCTION OF THE MENTALLY ILL FIGURE
}

\title{
Resumo
}

Este trabalho, seguindo uma perspectiva arqueogenealógica de Michel Foucault, tem o objetivo de investigar a figura do doente mental definidas pelas práticas e pelos discursos médico/psicológicos emergentes nos séculos XVII-XVIII, tal como a prática de internamento dos alienados; e no século XIX, com o advento da anatomopatologia, isto é, uma nova racionalidade médica pautada na objetivação da relação médico-paciente, como uma prática clínica. Esta pesquisa será realizada em três partes correspondentes às investigações de Foucault sobre suas obras, entre elas, História da Loucura, Nascimento da Clínica e O Poder Psiquiátrico. A partir dos estudos apresentados em História da Loucura, direcionamos as nossas análises para os séculos XVII e XVIII. A História da Loucura é um livro que faz uma arqueologia de uma percepção social do louco. Em Nascimento da Clínica, é apresentada uma arqueologia do olhar positivo. Por último, entraremos na genealogia Foucaultiana com O Poder Psiquiátrico para averiguarmos os desdobramentos históricos do século XIX sobre os dispositivos que efetuaram a produção da figura do doente mental.

Palavras-chave: Arqueogenealogia., despsiquiatrização., disciplina., figura do doente mental., medicina moderna.

\section{Abstract}

This paper,following an archeogenealogical perspective of Michel Foucault, aims to investigate the mentally ill figure defined by the emerging medical/psychological practices and discourses in the 17th and 18h centuries, such as the practice of internment of the alienated; and in the 19th century, with the advent of anatomopathology, i.e. a new medical rationality based on the objectification of the doctor-patient relationship, as a clinical practice. This research will be conducted in three parts corresponding to Foucault's investigations of his works, including History of Madness, Birth of the Clinic and Psychiatric Power. From the studies presented in History of Madness, we directed our analysis to the 17th and 18th centuries. The History of Madness is a book that makes an archeology of a social perception of the insane. In Birth of the Clinic, an archeology of the positive look is presented. Finally, we will enter the Foucaultian genealogy with Psychiatric Power to ascertain the historical developments of the 19th century about the devices that produced the mentally ill figure.

Keywords: Archeogenealogy., depsychiatrization., subject., mentally ill figure., modern medicine.

\footnotetext{
1 Graduado em psicologia pela Universidade de Fortaleza; Brasil; adrianohbezerra@gmail.com; https://orcid.org/0000-0003-1806-4531; Bairro Benfica; Avenida carapinima 1772; Edifício Solar dos Evangelistas.

2 Professora doutora titular do Programa de Pós-Graduação em Psicologia da Universidade de Fortaleza; Brasil; claravirginia@unifor.br.
} 


\section{INTRODUÇÃO}

O propósito deste trabalho é refazer uma arqueogenealogia para investigar a construção de discursos e imagens pelos quais o louco adquiriu forma e status. Trata-se da constituição de um campo científico-político, ético e epistemológico, na qual os loucos adquiriram estatuto de doentes mentais. Seguindo por esse caminho, vamos nos ater a três livros de Michel Foucault, quais sejam, História da Loucura, Nascimento da Clínica e O Poder Psiquiátrico. O objetivo desta pesquisa é investigar a definição da figura do doente mental como objeto da psiquiatria e da psicologia, como também da percepção social. Trate-se, assim, de um estudo sobre o surgimento do doente mental como uma figura antropológica, quer dizer, como uma figura definida pelos saberes, pelas práticas e pelas tecnologias sociais.

A figura do doente mental foi diagnosticada por meio da prática de internamento dos loucos em uma instituição fechada, o "Hospital Geral", no século XVII, construindo, dessa maneira, um espaço e uma percepção social de exclusão da loucura. Tomando por evidência esse acontecimento, a psiquiatria, a psicologia e as ciências humanas surgiram produzindo em torno dessa figura do excluído uma série de discursos, práticas institucionais e técnicas. Assim, à luz da arqueologia foucaultiana, o doente mental é tematizado como uma construção cultural, e não, portanto, tal como os manuais de psiquiatria, como uma descoberta científica/médica, pela qual o louco é libertado das correntes e da ignorância.

Nessa perspectiva, segundo Machado (2006), a doença mental é uma construção cultural, assim: "A psiquiatria é uma 'ciência' recente - a doença mental tem pouco mais de 200 anos - e que a intervenção da medicina em relação ao louco é datada historicamente" (p. 55). Ele ainda afirma que, "(...) não é mais possível falar rigorosamente de doença mental antes do final século XVIII, momento em que se inicia o processo de patologização do louco" (p. 52). Se, no final do século XVIII, não é possível falar com rigor sobre a noção de doença mental, então quais foram os processos históricos que tentaram instituir rigorosamente essa noção?

Os loucos, no Classicismo (séculos XVII e XVIII), mantiveram-se em uma posição entre a elaboração dedutiva de teorias da medicina mental e a percepção que incidiu sobre eles por meio de um nível institucional. Nesse quesito, é importante evidenciar que as possibilidades de surgimento da psiquiatria se deram mais por níveis institucionais do que teóricos. A obra "História da Loucura" também procura mostrar as vicissitudes que os loucos sofreram no decorrer dos séculos. Antes da época clássica, os loucos eram considerados errantes detentores de um saber advindo de outros lugares. Depois do Renascimento, os loucos, nos séculos XVII e XIII, foram percebidos como sujeitos desarrazoados que não possuíam a capacidade de transmitir uma verdade. Outra forma de perceber quem era louco na sociedade da época foi considerá-los como criminosos (Marquês de Sade é um exemplo) e depois como alienados. Nesse período, também surgiu um acontecimento conhecido como "O Grande Enclausuramento", resultando na exclusão dos loucos da vida social.

Com Pinel aconteceu uma outra manobra. Os loucos foram tirados das masmorras e transferidos para os asilos ou hospícios. Então, é por intermédio dessa transição efetuada por Pinel que os loucos começaram a ser enxergados de outra forma. Mas isso foi apenas o começo. A obra História da Loucura, como havia sido dito, mostra as possibilidades de surgimento da psiquiatria mais por graus institucionais do que teóricos. A figura do doente mental, no século XIX, foi produzida por meio de disciplinas de caráter pedagógico e técnicas, por exemplo, o interrogatório e a hipnose, cujo intuito era trazer a cura ao indivíduo. Um exemplo disso foram os tratamentos punitivos com duchas 
que Leuret usava como manejo moral para trazer a cura ao senhor Dupré. Isso foi exemplo das primeiras formas de tratamento da psiquiatria no século XIX. A segunda forma de tratamento se deu por meio de Charcot pela formulação do conceito de trauma e pela técnica da hipnose.

Outro território importante para ser demarcado foi o surgimento da anatomoclínica. Com advento da anatomoclínica, o olhar do médico foi direcionado ao corpo do doente e às suas lesões orgânicas. As formulações das doenças não se deram mais a partir de um olhar de superfície (como era feito na medicina mental da época clássica), mas o olhar do médico foi desviado a penetrar a profundidade do corpo doente. A demarcação desse território da anatomoclínica ganha importância porque é por meio dele que a psiquiatra encavalou-se para legitimar a doença mental como verdade. No entanto, a psiquiatria acabou por falhar em encaixar a doença mental em uma sintomatologia médica geral, pois não havia marcadores biológicos que evidenciassem o enfermo. 0 resultado disso foram as criações de algumas técnicas, como a técnica do interrogatório, os manejos reeducativos de caráter disciplinar e a hipnose.

Segundo Caponi (2007), Foucault atenta em estudar as percepções da loucura como fatores históricos e sociais no decorrer dos séculos XVII e XVIII, período esse conhecido como Classicismo. Mais tarde, a ideia de representação será deslocada para os dispositivos de poder, que são efeitos de práticas discursivas de produção do sujeito. O corpo, nas últimas décadas do século XIX, não foi mais cogitado a partir de tecidos e órgãos, mas começou a ser proferido como um corpo que deve adquirir comportamentos desejáveis.

Foi entre os anos 1850-1860 que se iniciou o discurso de um corpo neurológico. Esse corpo ainda estará localizado no âmbito da anatomoclínica, não existindo nenhuma forma de contradição entre eles. A anatomopatologia terá o objetivo de analisar profundamente o corpo doente. Por outro lado, a neurologia se limitou a descrever estímulos-repostas, ou seja, ficou encarregada de averiguar a superfície, sendo que, como havia sido apresentado, essas práticas no século XIX, em que a tendência era inscrever a loucura em uma sintomatologia médica geral, acabaram por falhar. Então, é por meio dos fracassos que o poder psiquiátrico começou a ganhar o palco para entrar em cena. A psiquiatria, portanto, não fez mais parte dos territórios do corpo neurológico e anatomopatológico (Caponi, 2007).

No âmbito das instituições, usadas como instrumentos de cura, quer dizer, um artifício de reeducação moral à alienação do louco, não surgem de descobertas científicas, e sim de necessidades sociais para manter a ordem da sociedade. A ideia de alienação criada por Pinel, após a Revolução Francesa (com a revolução o internamento, no período absolutista, deixa de ter caráter jurídico-político e passa a ter índole de tratamento), viabilizou uma manobra para produzir um tratamento moral, isto é, um processo pedagógico disciplinar por meio do hospício, cujo objetivo era fazer o louco retomar a razão e se tornar um cidadão. Consequentemente, o louco, por motivos de ter-se constituído a concepção de uma subjetividade alienada, será considerado como aquele que possui deficiências de cunho social (Amarante \& Torre, 2001).

$O$ ato de Pinel, aquele que libertou os loucos, possibilitou a criação de um território em que a psiquiatria ganhou legitimidade para germinar. A partir disso, a psiquiatria teve objetivo de manter a regularidade da ordem social por meio da moralidade e dos preceitos intelectuais. Ainda nessa perspectiva de estudo, Esquirol é outra efígie marcante que procurou anular as forças exteriores do louco por meio de terapias moralizadoras. Sob esse viés, Foucault (1997, p. 55) cita as cinco razões de Esquirol à exclusão dos loucos: “(...) 1) assegurar sua segurança pessoal e a de suas famílias; 2) libertá-los das influências externas; 3) vencer suas resistências pessoais; 4) submetê-los à força a um 
regime médico; 5) impor-lhes novos hábitos intelectuais e morais".

A loucura se encontrou inserida em mecanismos punitivos que havia no interior dos asilos do século XIX cujo objetivo foi reprimir o louco mediante valores morais. Os loucos foram culpabilizados por adotar comportamentos infantis, e sua psiquiatrização, por meio de mecanismo disciplinares, foi um elemento de um poder sobre o corpo que funcionaram para suprimir a vontade dos loucos. Seguindo por essa linha, este trabalho também servirá como ferramenta de reflexão para pensar, mediante os desdobramentos históricos, qual o intento das nossas práticas como profissionais de psicologia, até porque, de acordo com Foucault (2008, p. 88): "Nunca a psicologia conseguirá dizer sobre a loucura a verdade, porque a loucura é que detém a verdade da psicologia".

\section{METODOLOGIA}

O objeto de análise desta pesquisa se concentra na figura do doente mental à luz da arqueogenealogia foucaultiana; esse elemento de estudo foi analisado como uma realidade histórica e antropológica, quer dizer, produzido por práticas, discursos e instituições; o estudo dessa figura será feito por meio de um estudo teórico dos seguintes livros: História da Loucura, Nascimento da Clínica e O Poder Psiquiátrico. Na História da Loucura, procura-se evidenciar a emergência de uma experiência prioritariamente sociopolítica, ou seja, uma experiência do louco no meio social por meio do internamento no Hospital Geral. Então, nesse livro, Foucault demarca um campo discursivo, institucional e político no qual o louco ocupa lugar marginal acabando por ser excluído do contexto social. Não se pode esquecer também que as possibilidades de surgimento da psiquiatria se deram justamente por graus institucionais. É com Pinel que esse movimento foi orquestrado, retirando os loucos das masmorras e colocando-os em asilos ou hospícios.

Em Nascimento da Clínica, Foucault apresenta a transição do olhar médico. Ao invés de um olhar de superfície, como era na medicina mental da época clássica, o olhar foi direcionado para o corpo doente, isto é, um olhar de profundidade. Nesse sentido, a medicina empírica, por intermédio de Bichat e Broussais, detecta a doença no corpo, e não mais por meio de formulações superficiais como era a medicina clássica. É dessa forma que ocorre uma ruptura do modelo da clínica clássica para o modelo da clínica moderna: a anatomoclínica.

Com o advento da clínica moderna, a psiquiatria usou uma manobra no intuito de encavalar-se nos méritos da anatomoclínica. No entanto, os esforços da psiquiatria acabaram falhando ao tentar formular uma sintomatologia médica geral para a doença mental. É importante exprimir que doença é distinto de doença mental. É dessa maneira que $O$ Poder Psiquiátrico mostra, no decorrer do século XIX, duas fases que se apresentaram por meio de manejos morais disciplinadores, como os tratamentos de Leuret. Em um segundo momento, apareceram a técnica de hipnose e o conceito de trauma formulado por Charcot cujo objetivo era tentar, novamente, evidenciar fatores concretos da doença mental. A doença mental, diferentemente da doença (corpo lesionado), é uma produção, na qual os efeitos foram produzidos por meio dessas técnicas que foram criadas no decorrer do século XIX pela psiquiatria. Assim, a figura do doente mental é uma produção de uma tecnologia política dos indivíduos. 


\section{A PERCEPÇÃO SOBRE OS LOUCOS E AS POSSIBILIDADES DE SURGIMENTO DA PSIQUIATRIA}

A obra a História da Loucura não se trata de um livro cuja explicação pretende esboçar, rigorosamente, o nascimento da psiquiatria e o surgimento da doença mental, mas sim busca evidenciar os desdobramentos que possibilitaram a germinação desse campo mediante o nível da percepção. É nesse sentido que as análises de Foucault se concentram com maior consistência na época clássica, isto é, nos séculos XVII e XVIII (Machado, 2006).

Em suma, a obra História da Loucura apresenta uma crítica da razão que interpela as diversas formas que os loucos foram percebidos pelos graus institucionais e conhecidos por meio de formulações teóricas da medicina mental. O livro não se trata de uma história das ciências, porém mostra uma característica plural, visto que se propõe a explorar discursos que visam a se tornarem científicos e também discursos cujas qualidades são filosóficas, poéticas, políticas, literárias, etc (Machado, 2006).

De acordo com Foucault (2014):

O século XVIII percebe o louco, mas deduz a loucura. E no louco o que ele percebe não é a loucura, mas a inextricável presença da razão e da não-razão. E aquilo a partir do que ele reconstrói a loucura não é a múltipla experiência dos loucos, é o domínio lógico e natural da doença, um campo de racionalidade ( $p$. 187).

De acordo com esse preceito, como assim perceber o louco e deduzir a loucura? Há uma diferença sobre as noções de percepção e conhecimento, tendo em vista que percepção diz respeito às ações direcionadas em relação aos loucos, enquanto conhecimento, por outro lado, diz respeito à elaboração de vertentes teóricas no intuito de compreender a loucura como objeto cognoscível (Machado, 2006).

Nesse sentido, temos a definição de que a percepção sobre o louco se deu por vias institucionais, como a instauração do Grande Enclausuramento. No que tange à dedução da loucura, temos as formulações teóricas da medicina clássica por meio de uma base cartesiana. 0 modo da medicina clássica de tratar a doença era visto por meio do modelo de história natural, em que a doença era considerada como espécie natural, não sendo vista como um problema negativo, como um mal, que deve ser extirpado, tal como pensamos cotidianamente, mas como algo natural que deveria ser formulado por meio de classificações nosográficas inteligíveis, pois, como as plantas e as animais, as doenças também pertenciam ao mesmo reino; dessa forma, tinham uma natureza que devia ser estruturada mediante descrições taxonômicas, ou seja, o mundo das doenças dispõe de uma ordem equivalente ao mundo natural (Foucault, 2014).

Encontram-se, mesmo antes da psiquiatria do século XIX, consolidar a loucura como doença mental, quadros nosográficos que foram formulados nos séculos XVII e XVIII por Platero, Jonston, Boissier de Sauvages, Linné e Weickhard. De acordo com Machado (2006), "Trata-se de um jogo a que os médicos historiadores gostam de entregar-se: descobrir sob as descrições clássicas as verdadeiras doenças ali designadas" (p. 74). Nesse sentido, para completar e fortificar, Foucault (2014) corrobora:

Esse percurso na direção do ideal pode ser seguido de Platero a Linné ou Weickhard, e, aos poucos, pode-se ouvir uma linguagem se afirmando, na qual não se espera que a loucura formule suas divisões a não ser a partir de uma natureza que é ao mesmo tempo sua natureza e a natureza total de toda doença possivel (p. 193). 
Dessa maneira, a representação dos loucos estava entre as formulações teóricas da medicina da época clássica e a percepção institucional do Grande Enclausuramento. De um lado, temos formulações de caráter dedutivo sobre a loucura que procuravam formular um quadro de classificações inteligiveis para apresentar doenças com características abstratas; de outro, trazemos a percepção por meio do Grande Enclausuramento, cujo objetivo era o internamento dos loucos. Todavia, antes de apresentar alguns aspectos sobre o Grande Enclausuramento, serão expostas as vicissitudes que acometeram os loucos no decorrer do Renascimento até chegar à Modernidade.

Estamos perpassando, em primeiro lugar, para o Renascimento, em que os loucos eram vistos como aqueles que possuíam um saber esotérico e trágico, manifestando, por meio de suas errâncias, uma realidade de outro mundo. Nesse sentido: "Os loucos tinham então uma existência facilmente errante" (Foucault, 2014, p. 9). Na "Stultifera Navis", os errantes faziam jus às canções de um mundo dionisíaco. Os loucos aparecem como negatividade pura onde acabaram sendo capturados por referencias racionais. A razão detecta a negatividade dos loucos fazendo tudo que estiver ao seu alcance para barrá-la. Não mais como errantes que vasculham os mistérios do mundo, mas a figura do louco será percebida como o outro barrado (Machado, 2006).

O segundo momento ocorreu na Idade Clássica (séculos XVII e XVIII). Na época clássica, o domínio da razão sobre o louco se intensificou de maneira extrema. Já no Classicismo, o louco foi identificado como um sujeito de desrazão, desprovido da capacidade de pensar. A loucura, nesse período, foi julgada pelas organizações racionais de cunho cartesiano. Desse modo, os loucos, foram considerados os vacilantes da razão que levam ao erro.

O ponto decisivo a respeito do aspecto teórico é o aparecimento de uma consciência histórica da loucura. Isto é, enquanto a experiência da desrazão é afetiva, imaginaria, atemporal - afirma Foucault, sem no entanto fazer a análise -, a reflexão sobre a loucura é temporal, histórica, social (Machado, 2006, p. 65).

Foi também no Classicismo que o louco sofreu outra transformação. Ele foi percebido também como um criminoso a partir do momento em que surge a noção de alienação. Assim, o louco é alienado de sua verdade, mas essa verdade possui características criminosas. Essa época é bastante notória, pois é nela que Foucault denomina um acontecimento chamado $O$ Grande Enclausuramento. Todos aqueles que estavam fora dos padrões da normalidade clássica, como libertinos, mendigos, homossexuais, desocupados e etc, acabaram sendo internados (Machado, 2006).

Nesse contexto de estudo, a negatividade do louco, como aquele que se encontra fora dos moldes da razão e da moral, incita a manifestação desse alicerce positivo: o internamento. Essa positividade não diz respeito a uma condição de valor, mas remete a uma circunstância constituinte da realidade e de saber por meio da percepção. Nessa perspectiva de análise:

$O$ ato de internar não é algo negativo, no sentido de unicamente separar, isolar e excluir. É muito mais do que isso: ele é positivo, não no sentido, é evidente, de um juízo de valor, mas no de criador de realidade e de saber (Machado, 2006, p.58).

O período em específico que se inicia a trama do processo de internação dos loucos, sobre a ótica da razão, aconteceu a partir da metade do século XVII. De acordo com Foucault (2014), "Uma data pode servir de referência: 1656, decreto da fundação, em Paris, do Hospital Geral” (p. 49). O Hospital Geral também não é uma organização pautada por condições médicas, mas é uma ordem que se estabelece por meio de um arcabouço semijurídico. Foucault (2014) explana: "De saída, um fato é evidente: O Hospital Geral não é um estabelecimento médico. É antes uma estrutura semijurídica, uma espécie de entidade administrativa que, ao lado dos poderes já constituídos, e além 
dos tribunais, decide, julga e executa" (p. 50). É então que: "Alguns anos mais tarde, toda a igreja aprova a grande internação prescrita por Luís XIV" (Foucault, 2014, p. 60).

É importante lembrar, no Grande Enclausuramento, os loucos ainda não são percebidos como doentes mentais, então, o que se percebe, no Classicismo, é a desrazão. No Hospital Geral, não existe um tratamento de caráter medicinal com perspectivas científicas.

Sob esse aspecto, a individualização da loucura vai significar a criação de instituições destinadas exclusivamente aos loucos. 0 importante é que essa transformação do espaço de reclusão não se deve basicamente à medicina, mas a fatores políticos, econômicos e sociais (Machado, 2006, p. 66).

$O$ terceiro momento circunscreve-se na modernidade, ou seja, no transpassar da segunda metade do século XVIII para o século XIX, em que o louco foi observado como um alienado (noção essa que foi formulada na segunda metade do século XVIII) e depois será visto como doente mental. Loucura, na modernidade, concerne à psiquiatria, e é no interior de suas instituições que o louco se torna doente mental. É justamente nessa época que se constitui a elaboração da fábula de um homem normal. Agora, os loucos, saindo dos encarceramentos, serão colocados sob os cuidados médicos, e as correntes de ferro serão substituídas pelos medicamentos. Nesse caso, o louco será silenciado pelo monólogo da racionalidade psiquiátrica (Machado, 2006).

Na segunda metade do século XVIII, a loucura não foi mais vista como desrazão, e sim como alienação. É por intermédio dessa reflexão médico filosófica da segunda metade do século XVIII que os médicos começaram a tratar o homem como aquele que perdeu sua verdade. Verdade essa que não é exterior como se fosse um dado de realidade, mas uma verdade que se encontra no âmago do sujeito. A loucura, portanto, torna-se alvo de uma psicologização, de modo que, no interior daquele sujeito, há a existência de uma verdade a ser descoberta (Machado, 2006).

É importante ressaltar que, com o advento da interioridade psicológica, levando em consideração as peripécias da loucura, instalou-se uma consciência geradora de balbúrdia. Mas o que se encontrava nesse interior que gerava tanto escândalo? Qual era o grande mistério? Com o intuito de psicologizar a loucura, os motivos que levaram os alienistas ao interrogatório foi para descobrir o motivo dos fatos criminosos que tinham feitio subjetivo. "Introduzida no sujeito psicológico como verdade do crime, a loucura torna-se finalmente determinismo irresponsável" (Machado, 2006, p.70).

Segundo Machado (2006), "É sobretudo do lado institucional que Foucault vai desenvolver sua análise do nascimento da psiquiatria" (p. 72). As instituições são delineamentos que fazem perceber os loucos. É nessa transposição da maneira de perceber, ou seja, o louco da desrazão para o louco alienado, e depois como doente mental, que começaram a existir as teorias que fizeram conhecer a loucura como instância de ilegalidade, isto é, a verdade do crime. Ainda assim, esses não foram elementos (do conhecimento psiquiátrico) necessários para referir-se às transformações que ocorreram. Machado (2006) corrobora: "Mas, de todo modo, o conhecimento psiquiátrico calcado no conhecimento médico -, a elaboração de seus múltiplos sistemas, não é o componente fundamental da transformação" (p. 72).

A partir desses entendimentos, podemos compreender as circunstâncias de possibilidade da psiquiatria e os seus desdobramentos mais por fios institucionais do que teóricos. É por esse viés que a prática asilar ganha mais notoriedade do que a própria concepção de doença mental para entender a constituição da psiquiatria. Se, por um lado, a noção de loucura como doença mental instaura uma ruptura de vez com o Classicismo, por outro lado, a prática asilar nos ajuda a entender a ascensão da psiquiatria que se dá por transformações sociais, produzindo, dessa 
forma, a alienação mental. Nessa perspectiva, segundo Machado (2006): "A psiquiatria é, em última análise, uma relação de compromisso entre dois aspectos heterogêneos: o campo abstrato de uma natureza teórica e o espaço concreto de um internamento, ou, em outras palavras, uma 'análise médica' e uma percepção asilar' (p. 72).

Foi por meio das instituições que a locomoção da figura do louco desrazoado se concretizou em doente mental, quebrando, por conseguinte, os paradigmas da época clássica. Em suma, seu isolamento, sua individualização e sua patologização foram concernentes a condições de fatores que acabaram em impasses no âmbito da política e economia. (Machado, 2006).

O progresso do reconhecimento da loucura não ocorreu por meio do internamento dos loucos nem por causa de uma fixação da selvageria bestial. Esse reconhecimento acontece a partir do momento em que a loucura se afastou de tudo aquilo que a enclausurou. Pinel, mesmo sendo conhecido como aquele que libertou os loucos das correntes, não é considerado uma figura que suscitou a instauração de um novo modelo, no intuito de conhecer a loucura como doença mental.

Esse movimento foi adequadamente orquestrado, e não possibilitou de maneira nenhuma a libertação dos loucos. As estratégias criadas no interior do hospício, tais como a noção de cura pautada em uma terapêutica moral, para fazer que 0 alienado retomasse a sua verdade, foi uma alternativa para a transição da figura de um louco acorrentado (o enclausuramento) se encaminhar para um louco alienado. É dessa forma, "(...) que a psiquiatria pretende realizar, de modo mais perfeito, pelo sistema da recuperação, aquilo que no final do século XVIII o sistema clássico de exclusão se mostrou incapaz de realizar: o controle social do louco" (Machado, 2006, p. 81).

\section{O CORPO COMO ESPAÇO DA DOENÇA E O INDIVÍDUO DOENTE COMO OBJETO MÉDICO}

Em História da Loucura, Foucault mostrou uma dicotomia entre os níveis da percepção e do conhecimento. 0 objeto da arqueologia é a relação com os loucos no âmbito institucional do internamento. Essa relação diz respeito à percepção, e é por isso que Foucault, nessa obra em análise, faz uma arqueologia da percepção. Por outro lado, as teorias médicas, referentes à loucura, concernem ao nível do conhecimento. Se, por um lado, História da Loucura se trata de uma arqueologia da percepção, nascimento da clínica, por outro lado, é um livro que se dedica a uma arqueologia do olhar. De acordo com Foucault (2017) essa obra "(...) trata do espaço, da linguagem e da morte; trata do olhar (p. 7).

Já em Nascimento da Clínica, a análise principal se direciona para a medicina empírica, porém Foucault procura contrariar a ideia de que a medicina se tornou científica a partir do momento em que houve sua alteração para um saber empírico. Foucault não contesta que a medicina moderna seja empírica, mas ele critica a separação que os historiadores engendram entre a medicina empírica e a medicina clássica sem dar importância aos procedimentos teóricos e filosóficos (Machado, 2006).

Diante desse estudo, Foucault não tende a instaurar uma continuidade histórica na qual a ciência possui certa noção de progresso que nos levaria ao fim da evolução. Não! Os processos históricos são descontínuos e marcados por rupturas no campo dos saberes e dos conceitos. É dessa forma que o referido autor não procura marcar uma hierarquia, na qual a medicina moderna seja superior à medicina clássica. Nesse viés, o que, de fato, é relevante para Foucault são os procedimentos da produção de conhecimento. Essa análise é feita por meio de épocas díspares, 
mostrando os processos de elaboração no nível da linguagem e no nível da percepção, evidenciando como a clínica se tornou viável como ferramenta de conhecimento (Machado, 2006).

O objeto de estudo de Foucault em Nascimento da Clínica não é a loucura ou a doença mental, mas a própria doença e a medicina moderna. A ideia principal desse estudo mostra um momento de ruptura da medicina clássica para a medicina moderna. Assim, a medicina clássica foi um espaço de representação, classificação, olhar de superfície e taxonômico pautado no modelo de história natural, já a entrada na medicina moderna acontece quando 0 olhar foi orientando a entranhar-se na profundidade caliginosa das coisas, tendo em vista o objetivo de detectar a doença no espaço real do corpo (Machado, 2006).

A perspectiva da medicina clássica seguia uma linha para formular um espaço de racionalidade ideal da nosografia patológica. A doença era considerada uma essência que devia ser encontrada por meio de observações na natureza. Diante disso: "A doença é percebida fundamentalmente em um espaço de projeção sem profundidade, e de coincidência sem desenvolvimento" (Foucault, 2017, p. 4). É desse modo que a doença possuía uma estrutura natural equivalente a das plantas e a dos animais. Nessa medicina, ocorria o alheamento do doente e o foco era direcionado a um cacoete de classificação da doença com o intuito de constituir um espaço ideal na ordem das espécies. Acerca dessa análise, a examinação dos tecidos e dos órgãos lesionados não tinha importância (Machado, 2006).

Nessa perspectiva de estudo, Morgagni e Bichat foram importantes para a anatomia patológica no intuito de mostrar adequações para a clínica e de promover modificações em seu cerne. Contudo, existe uma diferença entre os dois, qual seja, Morgagni com suas concepções básicas visou às diferenças das doenças em órgãos atingidos, enquanto Bichat direcionou sua atenção para o espaço tissular. Então, Bichat fez um deslocamento, reduzindo a porção orgânica para a homogeneidade do espaço dos tecidos. É dessa forma que o olhar de superfície começa a se transformar em um olhar de profundidade, ou seja, a alteração da anatomopatologia, suscitada por Bichat, torna viável instituir a anatomoclínica. A partir de Bichat, a doença não foi mais considerada como uma essência ideal que se encontra em um quadro inteligível com classificações nosográficas, sendo, dessa forma, a visão da doença direcionada para os segredos do corpo. A análise da doença é real e profunda (Machado, 2006).

Acompanhada por essa dimensão empírica, a anatomoclínica infere a doença no interior do corpo, tornando visível aquilo que era invisível e permitindo uma transmutação na forma do olhar médico. A doença não se concentra mais em um espaço essencial nosográfico, todavia está inserida no espaço do organismo, e, como já havia sido apresentado, a doença, que era considerada uma espécie natural pelos moldes do paradigma botânico, será transmutada pelo modelo anatômico. A partir dos estudos de Pinel e Syndenham, a doença possuía uma organização universal racionalizada, mas, com Bichat, ela passa a ser sinalizada em um plano concreto, fazendo que a medicina largasse o medo da morte, pois a doença vive a partir do cadáver (Machado, 2006). "Abram alguns cadáveres: logo verão desaparecer a obscuridade que apenas a observação não pudera dissipar. A noite viva se dissipa na claridade da morte" (Foucault, 2017, p. 162).

Movendo a clínica à outra perspectiva, Bichat não foi o único que contribuiu para esse evento, e a locomoção para a clínica moderna com Bichat ainda não foi inteira. O passo decisivo para a transição foi assegurado por Broussais. Bichat direciona a atenção da medicina para a doença inserida nos tecidos do corpo, de tal maneira que ainda não há uma diferença entre a análise dos tecidos e a lesão orgânica. Nesse momento, a anatomoclínica não apresenta a indicação da doença como uma lesão no organismo. É justamente nesse instante que surge a importância de Broussais, pois ele encaminha a doença para inflamações orgânicas (Machado, 2006). 
De acordo com Broussais e seus estudos sobre as febres, há existência de diversas configurações de uma inflamação orgânica que ocorrem no interior de um tecido. Reconhecendo a seriedade de Broussais, foi possível, a partir dos recursos anatomoclínicos, promover uma relação distinta entre signo e sintoma, isto é, lesão orgânica e sintomas da doença. Se, na clínica, não existia diferença entre signo e sintoma, na anatomoclínica, de outro modo, 0 signo remete à novidade do organismo lesionado e não mais a uma essência patológica (Machado, 2006).

Então, pode-se dizer que a ruptura com a clínica do século XVIII se deu por intermédio de Bichat e Broussais. As inquietações de Bichat tinham o foco de estabelecer as doenças orgânicas de maneira geral, e Broussais, complementando a passagem para a clínica moderna, fez uma distinção dos sintomas para explicar causas particulares que promovem a irritação de um determinado organismo, ou seja, a doença é uma inflamação que se firma no organismo. É dessa forma que acontece uma transição do espaço da doença, isto é, a passagem de um espaço nosográfico para um espaço causal de fenômenos anatômicos e fisiológicos (Machado, 2006). "A partir de 1816, o olho do médico pôde se dirigir a um organismo doente. $\mathrm{O}$ a priori histórico e concreto do olhar médico moderno completou sua constituição" (Foucault, 2017, p. 214).

\section{A OBJETIVAÇÃO DA RELAÇÃO MÉDICO-PACIENTE; A OBJETIVAÇÃO DO DOENTE MENTAL}

Em O Poder Psiquiátrico (2006), Foucault apresenta algumas críticas a si mesmo. Nesse livro, o autor faz uma espécie de "back-ground" no intuito de interromper o trabalho que tinha feito em História da Loucura. A primeira crítica é direcionada às análises de representações, nas quais diz que ficou interessado em estudar a imagem que a loucura apresentava nos séculos XVII e XVIII. Ele mostra que essa esfera de representação era esboçada pelos modelos da medicina botânica, naturalista, etc. Esses modelos foram o enfoque das práticas que efetuaram a percepção da loucura nos séculos XVII e XVIII. Todavia, Foucault (2006) não procura mais se preocupar com esse campo de representação, assim, o que acaba acontecendo em seu trabalho é uma transição da representação para os dispositivos de poder, isto é, produção de práticas discursivas que apresentam um jogo de verdade. Isso significa que Foucault procurou analisar os dispositivos de poder sobre o corpo do doente mental.

Se, em 1816, findou-se o ser da doença, por outro lado, em 1817, começa a se pensar em um asilo ideal a partir de Fodèrè, e, dentro desse contexto, impera a ordem, a instauração da lei e o regimento do poder. É também nessa data do século XIX que a proto-história da psiquiatria começa a germinar a partir de algumas obras iniciais. Temos discursos/documentos analisados por Foucault, por exemplo, o Tratado médico- filosófico de Pinel e os artigos sobre a doença mental de Esquirol. Assim como 0 asilo ideal proposto por Fodèrè, temos também uma obra de sua autoria que se intitula o Tratado do Deíliro que data também 1817. Já em 1818, com Esquirol, o saber psiquiátrico começa a se inscrever no campo médico com o intuito de auferir legitimidade (Foucault, 2006).

A proto-história da psiquiatria também pode ser dividida em dois momentos, quais sejam, o primeiro momento surge com Pinel tirando as correntes dos loucos furioso nas profundezas de uma masmorra situada em Bicêtre. Essa cena protopsiquiátrica se dilata nos últimos anos do século XVIII, especificamente é a cena de 1792 que mostra Pinel adentrando as masmorras para tirar as correntes dos loucos furiosos, entretanto a cena de libertação de Pinel teve dois preços. Os loucos pagaram sua libertação pela obediência, submetendo sua vontade ao poder do alienista, e o segundo pagamento foi efetuado por meio da disciplina, tendo em vista a possibilidade de trazer a cura 
para o doente (Foucault, 2006).

Outra cena protopsiquiátrica seria um conjunto de casos apresentados a partir das primeiras décadas do século XIX por Haslam, Pinel, Fodèrè, Georget e Guislain, que acabaram tornando-se um marco para compreender como funcionaram os procedimentos de cura por intermédio da disciplina. Um exemplo disso seria outra cena protopsiquiátrica, ou seja, a cena de Jorge III (rei da Inglaterra) que teve um surto de mania e foi despossuído de seu trono, acabando sendo submetido a um regimento disciplinar para que recuperasse sua sanidade, isto é, para que fosse curado (Foucault, 2006).

Depois de algumas cenas protopsiquiátricas, temos duas fases da psiquiatria que surgiram durante 0 século XIX. A primeira fase da psiquiatria se apresentou por meio de tratamentos morais. De acordo com Foucault (2006), Leuret foi uma figura de grande importância para reforçar esse tipo de tratamento que permeou durante os anos 1840-1870. Depois dos tratamentos de caráter moralizadores, punitivos e disciplinares, surgiu uma nova prática que operou sobre os fenômenos histéricos, ou seja, a hipnose de Charcot.

No que diz respeito aos estudos de Leuret, considerado o homem do tratamento moral, este aplicava punição com ducha ao Sr. Dupré. De acordo com Foucault (2006):

[...] certo número de dispositivos ou de manobras, que Leuret nunca teoriza e a propósito dos quais não dá nenhuma explicação que se fundamentasse seja numa etiologia da doença mental, seja numa fisiologia do sistema nervoso, seja inclusive, de modo geral, numa psicologia da loucura (p. 182).

Um ponto interessante a ser ressaltado é que o funcionamento do poder psiquiátrico ocorria por meio de um termo que pode ser encontrado nos textos de Leuret e Pinel. Esse termo, usado durante o século XIX, chama-se "direção de consciência". Esse direcionamento era um campo em que podia ser encontrado um conjunto de técnicas e objetos, que o psiquiatra coordenava as operações dos indivíduos. Além disso, a direção de consciência tem em vista dar realidade a um poder coativo. Em primeiro lugar, isso significa que a realidade ganha um valor impositivo para atingir a loucura. Os suplementos de poder dado à realidade foram uma artimanha cujo intuito é fazer que os loucos não driblem ou fujam da realidade (Foucault, 2006).

Afinal de contas, o asilo não proporcionou nenhuma elaboração teórica de cura, o que acabou sendo constituído, dentro do asilo, foi um conjunto de manobras táticas para disciplinar o alienado, em que a disciplina era 0 manejo que traria a cura. Também vale lembrar que as observações feitas no interior do asilo serviram de ingredientes para gerar uma nosografia, isto é, uma classificação de doenças mentais. No entanto, o discurso anatomopatológico não se ajustou às práticas psiquiátricas (Foucault, 2006).

A psiquiatria, no século XIX (nos primeiro 30 ou 40 primeiro anos), atuava como um suplemento de poder fornecido à realidade. Antes de ser considerada como método terapêutico, a psiquiatria é uma forma administrativa cuja intenção é gerir os corpos dos alienados. Assim, é girando em torno desse regime que a psiquiatria consegue enraizar suas manobras terapêuticas (Foucault, 2006).

É também no século XIX que aparecem dois polos do personagem médico: 0 cirurgião e o psiquiatra. No mundo médico do século XIX, o polo cirúrgico se manifesta com a anatomopatologia que se iniciou com as contribuições de Bichat. Por outro lado, temos o polo psiquiátrico atuando de maneira distinta, ou seja, por meio do corpo do psiquiatra e das marcas de saber e seus suplementos de poder dados à realidade, o polo psiquiátrico oferece, mediante ao maquinário asilar, uma terapêutica punitiva que visa à disciplinarização dos corpos, isto é, tem por objetivo a cura. A marcação do corpo dos loucos por meio da disciplina mostra de forma clara o jogo que circula 
na microfísica do poder asilar que tem por objetivo a sujeição dos loucos (Foucault, 2006).

No início do século XIX, a psiquiatria buscou ligações orgânicas que permitissem a ela contornar a doença em uma categoria de loucura. Seus diagnósticos, distintos da medicina orgânica, são diagnósticos absolutos, por isso se opõem aos diagnósticos diferenciais, no século XIX, por uma ausência de corpo. Os diagnósticos absolutos se encontram no campo das doenças mentais e inferem uma ausência de corpo (Foucault, 2006).

O termo ausência de corpo foi apresentado por Foucault (2006) para explicar como a técnica de interrogatório funcionava no ambiente asilar. Esse processo, que começou a funcionar a partir dos anos 1820-1830, permitiu fixar uma identidade submetendo o louco ao seu passado, fazendo parte de uma pesquisa para averiguar o passado do sujeito. Essa pesquisa autorizava o psiquiatra investigar os antecedentes de uma pessoa, permitindo indagar se os seus familiares apresentavam algum quadro de doenças que poderiam se manifestar mais tarde no doente.

Em 1855-1860, ocorre a formulação da degenerescência. Antes dessa data, não havia a existência da noção de hereditariedade patológica e degenerescência. A noção de hereditariedade, por outro lado, permitia dar corpo a doença mental por meio da família. Nesse sentido, Foucault usou um termo que ele nomeou de o corpo fantasmático da família, esse corpo pertencia a uma família que foi abalada por diversos números de doenças, sendo que esse corpo fantasmático da família não passava de uma substância meta-orgânica usada como desculpa para detectar supostas doenças mentais no sujeito (Foucault, 2006).

O médico, diferente do psiquiatria, procura fomentar suas atividades por meio dos diagnósticos diferenciais. No século XIX, o diagnóstico diferencial foi a grande ação das práticas médicas, fazendo que o psiquiatra não se torne necessário nessas práticas, pois a psiquiatria se encontrava em um estágio abaixo das práticas médicas. Nessa perspectiva, Foucault (2006) fundamenta a seguinte abordagem: "Trata-se, para o psiquiatra, de responder à pergunta: este indivíduo é louco ou não?" (p. 321). Pois bem, diferente da psiquiatria, o sinal do saber médico procura descrever a doença (que não possui a mesma característica da noção de doença mental) por meio de seus diagnósticos diferenciais. Já o ponto da psiquiatria é o da fição que emerge diante dos diagnósticos absolutos.

Se, por um lado, o hospital de medicina geral é um lugar que procurou mostrar os aspectos da doença, por outro lado, o hospital psiquiátrico procura dar realidade à loucura. É desse modo que podemos promover uma crítica institucional, pois o hospital psiquiátrico é fonte de fabricação da loucura. O hospital médico tem o objetivo de anular a doença, e o hospital psiquiátrico possibilitou a loucura surgir como realidade. Nesse sentido, a psiquiatria se esforçou durante o século XIX para criar um saber sintomatológico, tendo como base os paradigmas da medicina e as suas constatações, mas seus esforços não foram o suficiente, o que acabou fazendo que ela transitasse para o ponto da fiç̧ão e da simulação (Foucault, 2006).

Diferente do corpo psiquiátrico e do corpo anatomopatológico, vemos surgir um novo corpo; o começo de um novo dispositivo que pode ser nomeado de clínica neurológica. Na clínica neurológica, o corpo do doente é compreendido de uma forma distinta do corpo anatomopatológico. $O$ olhar neurológico é um olhar de superfície do corpo, o que acaba lembrando bastante o modelo médico do século XVIII, e esse tipo de olhar foi reduzido, como já foi apresentado, a um olhar de profundidade pela anatomoclínica. Porém, não existe oposição entre corpo neurológico e anatomopatológico, pois um faz parte do outro (Foucault, 2006).

Conforme visto nas explanações acima apresentadas, uma das técnicas disciplinares da psiquiatria foi 0 interrogatório, sendo que a neurologia, surgindo como um novo dispositivo, diferiu-se desse método psiquiátrico. 0 mecanismo utilizado pela neurologia se deu por meio de instruções e injunções para que, por meio da vontade do 
doente, o dispositivo neurológico pudesse se tonar eficaz para coletar as respostas manifestantes. A neurologia também possibilitou a condição de viabilizar diagnósticos diferenciais, mas ela não possui as mesmas características do exame psiquiátrico e anatomopatológico. Não podemos esquecer também que a histeria se encontrou no interior desse dispositivo (Foucault, 2006).

Nos dois primeiros terços do século XIX, houve uma fronteira entre o saber médico e a prática médica. Essa fronteira apareceu por causa dos diagnósticos absolutos e dos diagnósticos diferenciais. Os diagnósticos absolutos mantinham certo binarismo no que tange à doença mental, ou seja, interrogava-se se o doente era louco ou não, e esse tipo de diagnóstico se dava por meio das provas de realidade. Os diagnósticos diferenciais, por outro lado, julgavam as doenças consideradas verdadeiras, isto é, aquelas doenças que podiam ser detectadas por identificar uma lesão no corpo doente. Contudo, Foucault afirma que, entre os anos 1820-1880, não houve uma oposição entre doenças orgânicas e doenças psíquicas. Os psiquiatras da década de 1820 até os anos 1870-1880 acreditavam que as doenças do espírito também faziam parte do corpo, ou seja, o corpo era fonte de sintomas e síndromes psíquicas, e, com o advento da clínica neurológica, cria-se a possibilidade de fazer que a histeria se torne uma doença mental (Foucault, 2006).

Diante desses estudos, Charcot aparece determinado em fazer que a histeria se torne uma doença. Qual o motivo dessa atitude? 0 motivo era o seguinte: um médico só podia ganhar legitimidade se ele conseguisse mostrar uma doença por meio de uma sintomatologia. 0 médico precisava desses sintomas para se tornar neurologista e, caso não conseguisse, seria rebaixado ao estatuto de psiquiatra (Foucault, 2006). Podemos até inferir que essa foi a grande ânsia da psiquiatria desde Pinel. Sob esse viés, Foucault (2006) menciona Freud:

E no fundo, creio que Freud pensava a mesma coisa quando aproximava Charcot de Pinel: Pinel libertou os loucos das correntes, isto é, ele fez que fossem reconhecidos como doentes. Pois bem, Charcot também fez que os histéricos pudessem ser reconhecidos como doentes. Ele os patologizou (p. 400).

No entanto, os diagnósticos diferenciais nunca conseguiram ser aplicados à loucura, ou melhor, os diagnósticos da clínica neurológica não conseguiam estipular a doença mental, assim, a loucura só era possível mediante os diagnósticos absolutos da psiquiatria.

Charcot iniciou a hipnose em 1878. No que tange à prática da hipnose, existiram duas vias para identificar a consideração do traumatismo. Se o traumatismo apresenta os mesmos sintomas que apareciam na histeria, o caso acabava sendo validado, mas, se o trauma não apresentar os mesmos sintomas, ele acabava caindo no campo dos simuladores. É dessa forma que ocorre uma espécie de naturalização da histeria por causa do traumatismo. Também existiram casos de pessoas que eram hipnotizadas e pessoas que não eram. Caso os sintomas traumáticos surgissem em uma pessoa que não estava sob o efeito da hipnose, isso assinalava que os sintomas encontrados podiam ser considerados naturais em uma pessoa que se encontrava hipnotizada (Foucault, 2006).

Nessa perspectiva, de acordo com Foucault, as histéricas foram usadas como manequins funcionais (termo usado por Foucault) para comprovar doenças de caráter não lesional. 0 conceito de traumatismo veio de Charcot justamente para atar o conceito a um nível etiológico, e essa manobra permitiu que as histéricas fossem usadas como parâmetro para detectar os simuladores, pois se acreditou que as histéricas escapavam de qualquer simulação. Portanto, a elaboração da concepção de traumatismo, proveniente de Charcot, foi usada para formular um quadro patológico por meio da hipnose, cujo objetivo era afirmar que não havia nenhum tipo de forjamento no que diz respeito à histeria (Foucault, 2006). 
A cena traumática é um tipo de lesão invisível de cunho patológico, e a hipnose foi usada como método para encontrar a cena do trauma, na qual o principal objetivo era formular uma etiologia. Charcot, no fundo, sabia e não admitia que a histeria era uma simulação sexual. Então, por que ele não admitiu? Para demonstrar que a histeria era uma doença, os sintomas não poderiam fazer parte da simulação, além do mais, para ser considerada como doença, a histeria não podia apresentar características sexuais. A fim de ilustrar essas ocorrências, Foucault (2006) cita um episódio que acontece no inverno de 1885-1886, o qual mostra quando Freud foi convidado a ir à casa de Charcot. Freud escutou de Charcot: "Oh! A histeria! Todo mundo sabe que é de sexualidade que se trata! E Freud comentou dizendo: Quando ouvi isso, fiquei surpreso e me perguntei: Mas, se ele sabe, por que não o diz?" (p. 417).

Como havia sido apresentado anteriormente, os manejos da psiquiatria, no decorrer do século XIX, dividiram-se em duas partes: primeiro, por meio de tratamentos disciplinadores para instaurar uma pedagogia moral que trouxesse a cura para sujeito; segundo, a técnica da hipnose advinda de Charcot, em que o propósito era detectar uma suposta doença inorgânica causada por um determinando trauma que acometeu a vida de uma pessoa.

Depois de Charcot, apareceram os movimentos de despsiquiatrização. Um desses movimentos teve o objetivo não de anular o poder médico, mas de retirar a psiquiatria desse perímetro da medicina para formular novas medidas, ou seja, fomentar uma manutenção da medicina. De acordo com Foucault (1997): "Despsiquiatrizar a medicina mental para estabelecer, na sua justa eficácia, um poder médico a qual a imprudência (ou ignorância) de Charcot tinha levado, abusivamente, a produzir doenças; portanto, falsas doenças" (p. 52).

É dessa forma, pensando por meio dessas técnicas da psiquiatria, no século XIX, que o poder dos asilos ou hospícios ofereceu aos psiquiatras a capacidade de produção. Esse tipo de produção diz respeito à doença mental mediante os diagnósticos absolutos. Não se pode esquecer também de que a psiquiatria se encavalou nos méritos da anatomoclínica para legitimar suas práticas. No entanto, como havia sito apresentado, a psiquiatria não conseguiu expor uma sintomatologia medica geral, tendo em vista que os diagnósticos absolutos da psiquiatria não possuem dados etiológicos. Assim, o cenário teatral da psiquiatria demonstra apenas a verdade de uma mera ficção.

Ainda sobre as estratégias de despsiquiatrização, que apareceram depois de Charcot e têm um primeiro movimento com Joseph Babinski, a psiquiatria procurou ser descolada do saber médico.

Uma primeira forma de despsiquiatrização começa com Babinski, em quem ela encontra seu herói crítico. Mais do que procurar produzir teatralmente a verdade da doença, é melhor procurar reduzi-la à sua estrita realidade, que talvez seja, frequentemente, apenas a aptidão para se deixar teatralizar: pitatismo (Foucault, 1997, p.52).

Desse modo, é importante evidenciar também a ideia de antipsiquiatria, na qual o poder psiquiátrico não deve ser encarregado de produzir a verdade da doença mental, ou melhor, do sofrimento, e promover essa manutenção do poder médico. Despsiquiatrizá-lo e tirá-lo, portanto, do perímetro no qual se situam os hospícios. No que tange aos hospícios, mecanismos de poder que procuram atender os requisitos de uma classe dominante para proteger a ordem social das desarrumações dos loucos (considerados como uma ameaça), esses foram posicionados sob questionamento por meio de Franco Basaglia no século XX (Foucault, 1997).

O sujeito não pode ser entendido como algo concedido, no entanto é produzido. No caso da psiquiatria, há uma subjetividade construída como doença mental, porém é relevante notar que a produção de subjetividade detém dois tipos de implicações: naturalizar ou desnaturalizar saberes ou instituições sociais. No que se refere à psiquiatria, sua produção tende a naturalizar. Eis um ponto fundamental: não se pode adquirir a tendência em considerar apenas uma 
forma de vida como natural, visto que a produção de subjetividade funciona forjando novos modos de existência. Inventar novas formas de vida é uma produção de subjetividade. Os sujeitos são de caráter histórico-estético, sendo capazes de tecer sua autopoiese. O manejo do saber não pode ser utilizado como técnica de normalização, mas como possibilidade de criação de subjetividade, pois as mazelas do sujeito trazem consigo a radicalidade de uma gênese subjetiva dissímil (Amarante \& Torre, 2001).

\section{CONSIDERAÇÕES FINAIS}

Podemos compreender como as formulações de classificações nosográficas funcionaram como métodos de normalização do sujeito. As práticas dos séculos XIX, por exemplo, os métodos disciplinares que foram usados no interior do asilo pelos psiquiatras foram uma forma de poder sobre o corpo que procurou docilizar a vontade dos loucos. A nosografia, o olhar de superfície, também serviram como manejos teóricos, mediante dados estatísticos, para concentrar uma esfera exígua de normalidade. Contudo, pode-se partir de um ponto em que a psiquiatria não conseguiu ainda encaixar a loucura em sintomatologia geral. A formulação de suas classificações nosográficas não passa de meros dados estáticos para conservar certo ideal de normalidade e trazer certa concepção de defender a sociedade daquilo que pode vir a ser considerado como anormal.

As funções da psicologia se encontram em todos os âmbitos, como escolas, presídios, organizações, etc. Cabe a nós pensarmos sobre as nossas práticas como profissionais de psicologia para não fazer da nossa prática um método de tentar normalizar ou enclausurar as formas de existência em catálogos nosográficos cujo intento seria patologizar e enquadrar o sujeito dentro de uma norma. Os indivíduos possuem histórias diferentes, e não é possível negar a singularidade de cada um, pois as experiências de vida trazem elementos diversos que não podem ser limitados apenas por um catálogo nosográfico que limita a existência.

Negar a história singular de cada pessoa é afirmar a condição de uma subjetividade naturalizada. As questões, assim como o sofrimento de cada um possuem instâncias que permitem uma determinada pessoa refletir ou ressignificar sua existência. A escuta sobre a história de uma pessoa é condição sine qua non na prática de cada profissional de psicologia. Nossas doenças psíquicas, nosso sofrimento, nossas mazelas possuem questões delicadas que não se limitam a apenas uma classificação nosográfica. A negatividade de nossas mazelas psíquicas possui um avesso que pode permitir o desabrochar de potencialidades. E como já disse Foucault, a psicologia não possui a verdade da loucura, mas é a loucura que possui a verdade da psicologia.

\section{Referências}

Amarante, P., Torre, E. H. G. (2001). Protagonismo e subjetividade: a construção coletiva no campo da saúde mental. Departamento de Administração e Planejamento, Escola Nacional de Saúde Pública, Fundação Oswaldo Cruz. Av. Leopoldo Bulhões, 1.480/70 andar - 21041-210 - Manguinhos - Rio de Janeiro - RJ.

Caponi, S. (2007).Michel Foucault e a persistência do poder psiquiátrico. Departamento de Saúde Pública, Universidade Federal de Santa Catarina. Campus Universitário Trindade. 88040-900 Florianópolis SC. 
Foucault, M. (1997). Resumos dos cursos do College de France (1970-1982) / Michel Foucault; tradução, Andréa Daher; consultoria, Roberto Machado. - Rio de Janeiro: Jorge Zahar Ed.

Foucault, M. (2006). O poder psiquiátrico: curso dado no Collège de France (1973-1974) / Michel Foucault; edição estabelecida por Jacques Lagrange, sob direção a direção de Françoise Ewald e Alessandro Fontana; tradução Eduardo Brandão; revisão técnica Salma Tannus Muchail, Márcio Alves Fonseca. - São Paulo: Martin Fontes.

Foucault, M. (2008). Doença mental e psicologia. Autor: Michel Foucault. Tradução: Hélder Viçoso. Grafismo: Cristina Leal. Paginação: Vitor Pedro. Edições Texto \& Grafia, Lda. (1.a edição).

Foucault, M. (2014). História da loucura: na idade clássica / Michel Foucault; [tradução José Teixeira Coelho Neto]. São Paulo: Perspectiva.

Foucault, M. (2017). O nascimento da clínica / Michel Foucault; tradução de Roberto Machado. - (7. Ed.) - Rio de Janeiro: Forense Universitária.

Machado, R. (2006). Foucault, a ciência e o saber / Roberto Machado. - (3 ed. rev.) e ampliada. - Rio de Janeiro: Jorge Zahar Ed. 